\title{
Pes Planus Tanısında Ayak İi ve Radyografik Ölçüm Yöntemlerinin Korelasyonu
}

\section{The Correlation Between Footprint and Radiographic Measurements in Flatfoot}

\author{
Kerem GÜN, Merih SARIDOĞAN, Ömer UYSAL* \\ Istanbul Üniversitesi Cerrahpaşa Tıp Fakültesi, Fiziksel Tıp ve Rehabilitasyon Anabilim Dalı, Istanbul, Türkiye \\ *Bezmialem Vakıf Üniversitesi Biyoistatistik ve Tıp Bilişimi Anabilim Dalı, Istanbul, Türkiye
}

\section{Özet}

Amaç: Bu çalışmada pes planus tanısında kullanılan 3 farklı ayak izi ölçümü ve 3 farklı radyolojik değerlendirme metodunun birbirleri ile korelasyonunun ortaya konması amaçlandı.

Gereç ve Yöntem: Üç yüz otuz sekiz hastane çalışanının statik ayak izleri Harris tabakası kullanılarak alındı ve Staheli Indeks (Si), Chippaux Smirak Indeks (CSI) ve Grivas Klasifikasyon Sistemi (GKS) kullanılarak değerlendirildi. Sl'ye göre pes planus tespit edilip ayakta yük vererek lateral ayak grafileri çekilen 52 olgunun grafilerinde kalkaneus zemin açısı (KZA), talus zemin açısı (TZA) ve talometatarsal açı (TMA) ölçüldü.

Bulgular: Çalışmada yer alan 338 olgunun 133'ü $(\% 39,4)$ erkek, 205'i $(\% 60,6)$ kadın, yaş ortalaması 38 $\pm 8,6$ yıl idi. CSi'ye göre $118(\% 34,9)$, Sl'ye göre $63(\% 18,6)$, GKS'ye göre $9(\% 2,6)$ olguda bilateral pes planus tespit edildi. Üç ayak izi ölçüm metodu arasında kuvvetli korelasyon tespit edildi (Si/CSI r:0,961, p<0,001, Si/GKS r:-0,876, p<0,001, CSI/GKS r:$0,886, p<0,001)$. Ancak pes planus tanısında ayak izi ölçüm yöntemlerinin olgularda aynı tanıyı koyup koymadıkları incelendiğinde yöntemlerin istatistiksel olarak $(p>0,05)$ uyumsuz olduğu anlaşıldı. Radyolojik ölçüm yöntemlerinden KZA ve TMA ile her 3 ayak izi ölçüm yöntemi arasında zayıf korelasyon gözlendi (KZA/SI r:-0,317, $\mathrm{p}=0,001, \mathrm{KZA} / \mathrm{CSI} \mathrm{r}:-0,420$, $\mathrm{p}<0,001, \mathrm{KZA} / \mathrm{GKS} \mathrm{r}: 0,462, \mathrm{p}<0,001, \mathrm{TMA} / \mathrm{Si} \mathrm{r}: 0,342, \mathrm{p}<0,001, \mathrm{TMA} / \mathrm{CSI}$ $r: 0,332, p=0,001, T M A / G K S r:-0,465, p<0,001)$. TZA ile ayak izi ölçüm yöntemleri arasında anlamlı korelasyon bulunmadı.

Sonuç: Farklı ayak izi ölçümü ve radyolojik değerlendirme yöntemleri, birbirleri ile korelasyon gösterseler de, pes planus tanısında uyumsuz sonuçlar ortaya koyabilmektedir. Türk Fiz Tıp Rehab Derg 2012;58:283-7. Anahtar Kelimeler: Pes planus; ayak izi; radyoloji; korelasyon

\section{Summary}

Objective: The aim of this study was to determine the correlation between 3 different footprint measurement procedures and 3 different radiological assessment methods in the diagnosis of pes planus.

Metarials and Methods: Harris Mat footprints of 338 hospital staff were taken and were evaluated by using 3 different measurement methods: Staheli index (SI), Chippaux-Smirak Index (CSI) and Grivas Classification System (GCS). In 52 patients who were diagnosed with pes planus according to the SI underwent lateral weight-bearing radiogram and calcaneal pitch angles (CPA), talohorizontal angle (THA) and talo-first metatarsal angle (TMA) were evaluated.

Results: Of the 338 patients, 133 (39.4\%) were male, and 205 (60.6\%) were female. The average age was $38 \pm 8,6$ years. Pes planus was determined in 118 patients (34.9\%) according to the CSI, in 63 (18.6\%) according to SI, and in 9 patients $(2.6 \%)$ according to GCS. There was a strong correlation between the three footprint measurement methods (SI/CSI $r: 0.961, p<0.001$, SI/GCS $r$ : $0.876, \mathrm{p}<0.001, \mathrm{CSI} / \mathrm{GCS} \mathrm{r}:-0.886, \mathrm{p}<0.001)$. However, when we investigated whether the footprint measurement methods can give the same pes planus diagnosis, we found that the methods are statistically discordant $(p>0.05)$. CPA and TMA had a low correlation with each of three footprint measurement methods. (CPA/SI r: $-0.317, \mathrm{p}=0.001, \mathrm{CPA} / \mathrm{CSI} \mathrm{r}:-0.420, \mathrm{p}<0.001, \mathrm{CPA} / \mathrm{GCS} \mathrm{r}$ : $0.462, p<0.001, T M A / S I$ r: $0.342, p<0.001, T M A / C S I r: 0.332, p=0.001$, TMA/GCS $r:-0.465, p<0.001)$. We have not observed a statistically significant correlation between THA and footprint measurement methods.

Conclusion: In the diagnosis of flatfoot, different footprint measurements and radiologic methods give incompatible results even though they may show correlation with each other. Turk J Phys Med Rehab 2012;58:283-7. Key Words: Flatfoot; footprint; radiology; correlation 


\section{Giriş}

Ayağın medial longitudinal ark (MLA) yüksekliğinin azalması veya tamamen kaybolması pes planus olarak tanımlanır (1-3). MLA değerlendirmesinde uluslararası kabul görmüş bir ölçüm yöntemi ve MLA'nın normal yüksekliği konusunda fikir birliği bulunmamaktadır. MLA'da meydana gelen yükseklik kayıpları, klinik muayene (4-6), somatometrik ölçüm $(7,8)$, radyolojik değerlendirme $(9,10)$ ve ultrasonografik inceleme $(11)$ gibi direkt yöntemlerle belirlenebilir. Diğer yandan, mürekkepli veya dijital ayak izi ve basınç ölçümleri $(3,12-14)$ ve fotografik teknikler (15) ark değişikliklerinin ortaya konmasında kullanılan indirekt yöntemlerdir. Pes planus tanısında kullanılan yöntem elde edilen insidans değerini de etkilemektedir. Bu yüzden literatürde bildirilen pes planus görülme sıklığı, kullanılan ölçüm yöntemine bağlı olarak, büyük farklılıklar göstermektedir $(5,14,16-19)$.

Bu çalışmada, pes planus tanısı için kullanılan 3 farklı ayak izi ölçümü ve 3 farklı radyolojik değerlendirme metodunun birbirleri ile korelasyonu araştırılmıştır.

\section{Gereç ve Yöntem}

Cerrahpaşa Tıp Fakültesi etik kurulu tarafından onay alan araştırma için hastanemizde görevli 364 kişi çalıştıkları birimlerde ziyaret edilerek çalışma hakkında bilgilendirildi. Çalışanlardan 17 kişi araştırmaya katılmak istemedi, 6 kişi yürümeyi engelleyen rahatsızlıkları (1 kişi parapleji, 3 kişi polio sekeli, 1 kişi total kalça protezi, 1 kişi hemofilik artropati), 3 kişi ise geçirmiş oldukları ayağa yönelik cerrahi girişim nedeniyle çalışmaya dahil edilmedi. Geri kalan 338 olgunun statik ayak izleri tek bir araştırmacı tarafından Harris Mat kullanılarak kaydedildi. Ayak izleri 3 farklı ölçüm yöntemi ile değerlendirildi.

1- Staheli İndeks (Si) : Ayak izinde orta ayağın en dar bölgesi ile topuğun en geniş bölgesi arasındaki oran. Indeksin 0,7'den büyük olması pes planus olarak kabul edildi (12) (Resim 1a).

2- Chippaux-Smirak İndeks (CSi): Orta ayağın en dar ve metatarsal alanın en geniş bölgesi arasındaki oran. İndeksin 0,4'den büyük olması pes planus olarak isimlendirildi (20) (Resim 1b).

3- Grivas Klasifikasyon Sistemi (GKS): Önce her ayak izinde aşağıda tanımlanan parametreler belirlendi (14) (Resim 1c):

a) Ayağın longitudinal aksı (LAF): Topuğun merkezinden 2. parmağa uzanan çizgi.

b) Kalkaneusun longitudinal aksı (LAC): Kalkaneal ovali ikiye ayıran çizgi.

c) Ayağın medial sınırı (M): Metatars ve topuğun en medial noktası arasında çizilen çizgi.

d) Orta ayak eni ( $Y$ ): $M$ çizgisine dik şekilde, arkın lateral dış kenarına çizilen çizgi.

e) Ark eni $(X)$ : Y çizgisine paralel, arkın medial sınırına çizilen çizgi.

Daha sonra bu parametrelerin birbiri ile olan ilişkilerine göre 6 farklı ayak tipi tanımlandı:

Tip I (Yüksek arklı ayak tipi): LAC LAF'ın lateralindedir ve ark izi yoktur $(x=y)$.

Tip II (Orta düzeyde yüksek arklı ayak tipi): $y>x \geq 3 / 4$ y.

Tip III (Normal ayak izi): $3 / 4 y>x \geq 2 / 4 y$.
Tip IV (Normal ayak izi): $2 / 4 \quad y>x \geq 1 / 4$ y ve LAC LAF'ın üzerinde/ lateralindedir.

Tip V (Düşük arklı ayak tipi): $1 / 4 \quad y>x \geq 0$ ve LAC LAF'ın üzerinde/ medialindedir.

Tip VI (Ciddi pes planus): $x$ > y ve LAC LAF'ın medialinde yer alır (14).

Ölçümler sonrası kliniğimizde pes planus tanısında rutin olarak kullanılan Si'ye göre pes planus tespit edilen 63 olgudan araştırmaya devam etmeyi kabul eden 52'sinde çekilen yük verilmiş lateral ayak grafilerinde, Simons (21) ve Vanderwilde (22) tarafından tanımlanmış 3 farklı yöntem ile radyografik ölçümler yapıldı. Bu ölçümler şunlardı:

1-Kalkaneus-zemin açısı (KZA): Kalkaneusun alt yüzünden çizilen teğet çizgi ile zemin arasındaki açı. Onbeş dereceden küçük olması pes planus olarak kabul edildi (Resim 2a).

2- Talus-zemin açısı (TZA): Midtalar çizgi ile zemin arasındaki açı. Otuz dereceden büyük olması pes planus olarak değerlendirildi (Resim 2b).

3- Talometatarsal açı (TMA): Midtarsal çizgi ile navikuler kemik ve 1. metatars şaftını birleştiren çizgi arasındaki açı. Dört dereceden büyük açılar pes planus olarak tanımlandı (Resim 2c).

Ayak izi değerlendirmeleri ve radyografik ölçümler, ayak izlerinin ölçümünde görev alan aynı araştırmacı tarafından yapıldı. Sayısal değişkenlerin birbirleri ile ilişkilerinin derecesi Pearson korelasyon katsayısı ile belirlendi. İkili değişken çiftlerin aynı yanıtı verip vermemeleri Mc-Nemar testi- Kappa testi kullanılarak değerlendirildi. Tüm istatistiksel analizler SPPS yazılımı (version 15.1, SPSS Inc, Chicago, IL) kullanılarak yapıldı. İstatistiksel anlamlılık kriteri $\mathrm{p}<0,05$ olarak kabul edildi.

\section{Bulgular}

Çalışmada yer alan 338 olgunun 133'ü $(\% 39,3)$ erkek, 205'i $(\% 60,7)$ kadındı. Olguların yaş ortalaması $38 \pm 8,6$ olarak tespit edildi. Olguların mesleklere göre dağılımı incelendiğinde 137

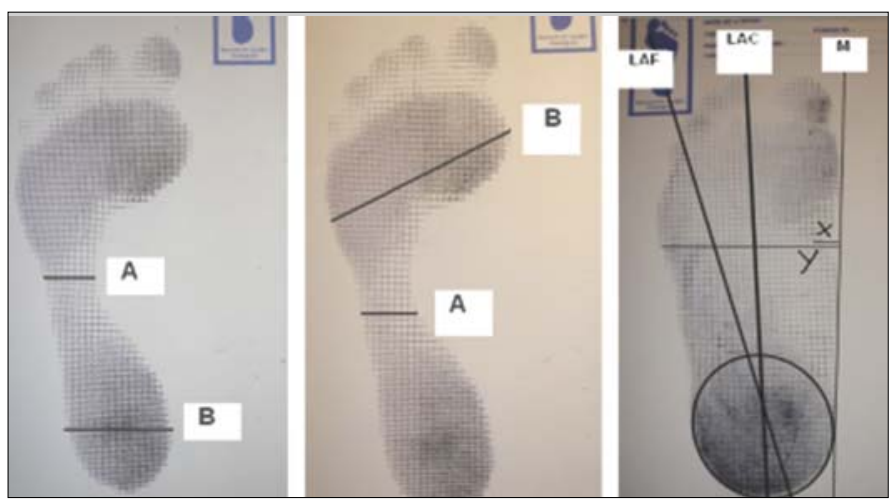

Resim 1. a) Staheli Indeksin hesaplanması:

A- Orta ayağın en dar bölgesi B-Topuğun en geniş bölgesi

b) Chippaux-Smirak Indeksin hesaplanması:

A- Orta ayağın en dar bölgesi B-Metatarsal alanın en geniş bölgesi c) Grivas Klasifikasyon Sistemi :

LAF (Ayağın longitudinal aksı): Topuğun merkezinden 2.parmağa uzanan çizgi. LAC (Kalkaneusun longitudinal aksı): Kalkaneal ovali 2 ye ayıran çizgi. M (Ayağın medial sınııı): Metatars ve topuğun en medial noktası arasında çizilen çizgi. $Y$ (Orta ayak eni): $M$ çizgisine dik, istmusun lateral dış kenarına çizilen çizgi. $X$ (Ark eni): $Y$ çizgisine paralel, arkın medial sınıına çizilen çizgi 
yardımcı sağlık personeli $(\% 40,5), 87$ memur $(\% 25,7) 76$ hemşire $(\% 22,5), 38$ doktor $(\% 11,2)$ olduğu görüldü.

CSI'ye göre $118(\% 34,9)$, Si'ye göre $63(\% 18,6)$, GKS'ye göre $9(\% 2,6)$ olguda bilateral pes planus tespit edildi (Tablo 1 ). Ölçüm yöntemlerine göre elde edilen en küçük (min), en büyük (maks) ve ortalama (ort) değerler şu şekilde idi: CSI'de min 0 , maks 0,73 , ort $0,35 \pm 0,13$, si'de min 0 , maks 1,38 , ort $0,60 \pm$ $0,21, G^{\prime} S^{\prime}$ de min 0,6 , maks 1,13 , ort $0,56 \pm 0.16$. Tek taraflı pes planus ise Si'ye göre 2, CSI'ye göre 13, GKS'ye göre 1 kişide mevcuttu.

Her pes planuslu ayak tek olgu olarak kabul edilerek istatistiksel analizler gerçekleştirildi.

Üç ayak izi ölçüm metodu arasında kuvvetli korelasyon tespit edildi (Si/CSi r:0,961, $p<0,001$, Si/GKS r:-0,876, $p<0,001$, CSI/GKS r:-0,886, $\mathrm{p}<0,001$ ) (Tablo 2).

Ayak izi ölçüm yöntemlerinin, "pes planus var mı ?" sorusuna verdikleri cevaplar yönünden yapılan incelemede CSI'ye göre pes planus tanısı almış 249 ayaktan 230'u GKS'ye göre tanı alamadı,

Tablo 1. Ayak izi ölçüm yöntemleri ile elde edilen bilateal pes planus sayısı yüzdesi. Olgu sayısı 338.

\begin{tabular}{llll} 
& CSI & SI & GKS \\
\hline Pes planus sayısı & 118 & 63 & 9 \\
Pes planus yüzdesi & $\% 34,9$ & $\% 18,8$ & $\% 2,6$ \\
\hline CSI: Chippaux Smirak Indeks, Si: Staheli Indeks, GKS: Grivas Klasifikasyon Sistemi
\end{tabular}

Tablo 2. Ayak izi ve radyolojik ölçüm yöntemlerinin birbirleri ile korelasyonları.

\begin{tabular}{lccccc} 
& SI & GKS & KZA & TZA & TMA \\
\hline CSI & r:0,961*,a & r:-0,886*,a & r:- $0,420^{*}, b$ & $r<025^{* *}, c$ & $r: 0,332^{*}, b$ \\
Si & $r:-0,876^{*}, a$ & $r:-0,317^{*}, b$ & $r<025^{* *}, c$ & $r: 0,342^{*}, b$ \\
GKS & & $r: 0,462^{*}, b$ & $r<025^{* *}, c$ & $r:-0,465^{*}, b$ \\
KZA & & & $r<025^{* *}, c$ & $r<025^{* *}, c$ \\
TZA & & & & $r<025^{* *}, c$
\end{tabular}

r: Pearson korelasyon katsayist, ${ }^{*} p<0,00,{ }^{* *} p>0.05$, a: kuvvetli korelasyon, b: zayiforta derecede korelasyon, c: ilişki yok.

CSI: Chippaux Smirak Indeks, SI: Staheli Indeks, GKS: Grivas Klasifikasyon Sistemi, KZA: Kalkaneus zemin açııı, TZA: Talus zemin açısı, TMA: Talometatarsal açı.

Tablo 3. Ayak izi ölçüm yöntemlerinin pes planus tanısı koyma veya koymama yönünden karşıllaştırılması. Ayak sayısı 676.

\begin{tabular}{cccccc} 
& & \multicolumn{3}{c}{ CSI } & GKS \\
& & $\mathrm{Pp}(+)$ & $\mathrm{Pp}(-)$ & $\mathrm{Pp}(+)$ & $\mathrm{Pp}(-)$ \\
\hline \multirow{2}{*}{ Si } & $\mathrm{Pp}(-)$ & 123 & 425 & 1 & 547 \\
& $\mathrm{Pp}(+)$ & 126 & 2 & 18 & 110 \\
\multirow{2}{*}{ CSI } & $\mathrm{Pp}(-)$ & & & 0 & 427 \\
& $\mathrm{Pp}(+)$ & & & 19 & 230 \\
\hline
\end{tabular}

Pp: Pes planus, CSI: Chippaux Smirak Indeks, Si: Staheli Indeks, GKS: Grivas Klasifikasyon sistemi.
GKS ile tanı alan 19 ayağın ise tamamı CSI'ye göre pes planus olarak tanımlandı. Aynı şekilde CSi ile tanı konmuş 249 ayaktan $123^{\prime}$ ü Si' e göre pes planus olarak sınıflandırılabildi. Sí ye göre pes planus kabul edilen 128 olgunun ise 2'si dışında tamamı CSI'ye göre pes planus olarak tanımlandı. Bu 128 ayağın $110^{\prime} u$ GKS'ye göre belirlenmiş pes planus tanı oranını sağlamadı. GKS'ye göre pes planus olan 19 ayağın ise sadece 1'i Si'ye göre normal sınırlar içinde yer aldı. Ölçüm yöntemleri arasında zayıf ve orta düzeyde uyum tespit edildi (Si/CSI: $\mathrm{k}: 0,569, \mathrm{p}<0,01$, Si/GKS: к: 0.178, p<0,01, GKS/CSi:k: 0.264, p=0,04) (Tablo 3).

Si'ye göre pes planus tespit edilen 63 olgudan araştırmaya devam etmeyi kabul eden 52 'sinde çekilen yük verilmiş lateral ayak grafilerinde yapılan radyolojik ölçüm yöntemlerinden KZA, TMA ve TZA ile elde edilen en küçük, en büyük ve ortalama değerler şu şekideydi: $K Z A^{\prime}$ da min 6 , maks 29 , ort $17,3 \pm 4,3$, $\mathrm{TMA}^{\prime}$ da min 0 , maks 21 , ort $8 \pm 5,4, \mathrm{TZA}^{\prime}$ de min 21 , maks 41 , ort $28,8 \pm 5,0$. KZA ve TMA ile her 3 ayak izi ölçüm yöntemi arasında zayıf korelasyon gözlendi (KZA/Si r: -0,317, p=0,001, KZA/CSi r:$0,420, p<0,001, K Z A / G K S$ r:0,462, p<0.001, TMA/Si r: 0,342, $p<0,001, T M A / C S i \quad r: 0,332, p=0,001$, TMA/GKS $r:-0,465$, $\mathrm{p}<0.001)$. TZA ile ayak izi ölçüm yöntemleri arasında anlamlı korelasyon bulunmadı (Tablo 2).

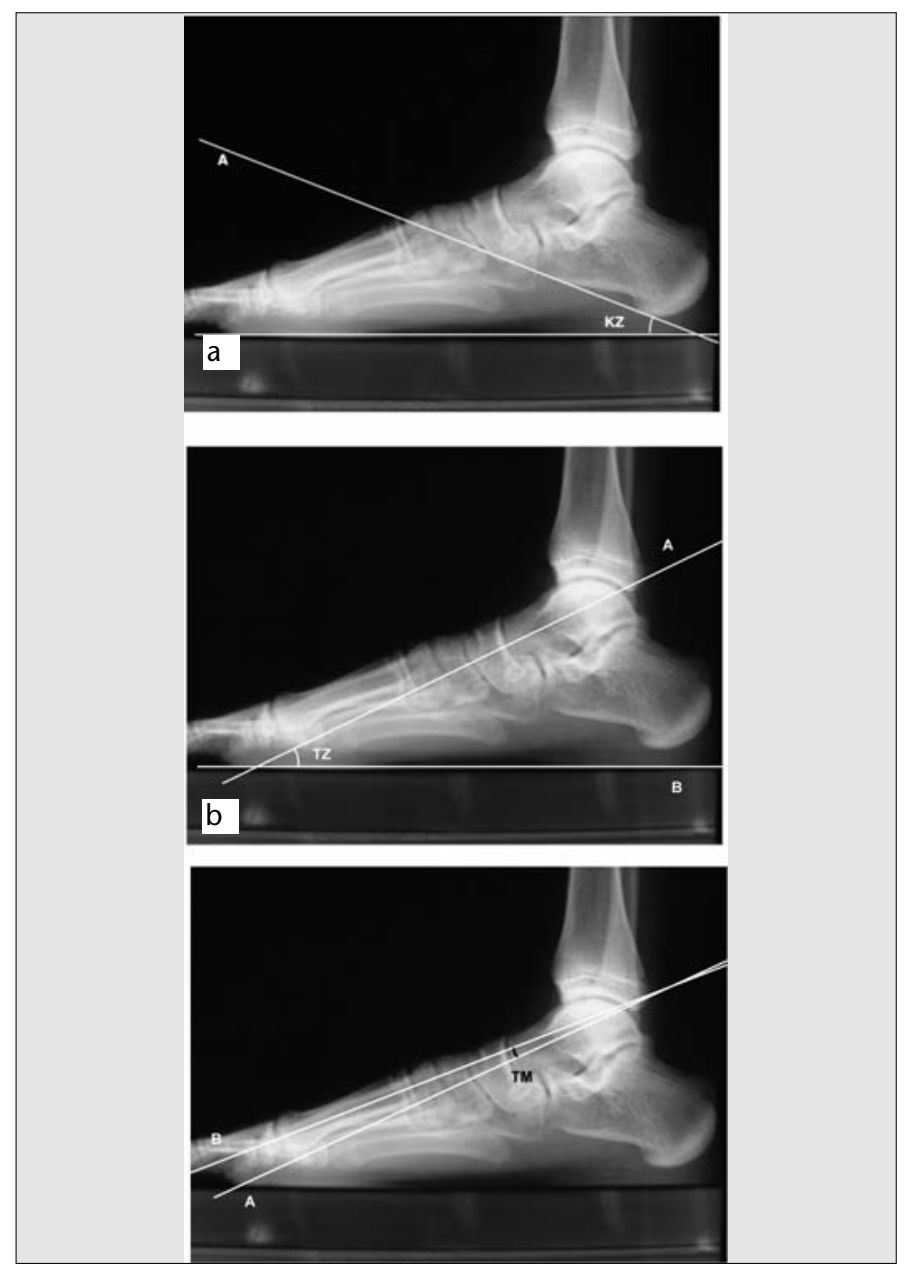

Resim 2. a) Kalkaneus-zemin açısı (KZA): Kalkaneusun alt yüzüne teğet çizilen çizgi (A) ile zemin (B) arasındaki açı. b) Talus-zemin açısı (TZA): Midtalar çizgi (A) ile zemin (B) arasındaki açı. c) Talometatarsal açı (TMA): Midtarsal çizgi (A) ile navikuler kemik ve 1.metatars şaftını birleştiren çizgi (B) arasındaki açı. 
Kappa testi ile tanı koymada uyumları incelendiğinde ise radyolojik ölçüm yöntemleri ile ayak izi ölçüm yöntemleri arasında KZA ve GKS dışında ancak ortanın altında ve zayıf uyum bulundu $(K<0,4)$. KZA ve GKS arasıda ise iyi düzeyde uyum tespit edildi $(\kappa: 0,618, \mathrm{p}<0,05)$.

\section{Tartışma}

Ayağın MLA yüksekliğinin azalması veya tamamen kaybolması pes planus olarak tanımlanır $(1,2)$. MLA değerlendirmesinde tanımlanmış pek çok yönteme rağmen, uluslararası kabul görmüş bir ölçüm metodu ve MLA'nın "normal" yüksekliği konusunda fikir birliği bulunmamaktadır. Ayak izi incelemesi, MLA'nın morfolojik bozukluklarının tanısı ve takibinde eski ve üstünde çok çalışılan bir yöntemdir $(3,4,9,23)$. Bu yöntem, ucuz, kolay uygulanabilir ve nispeten objektifdir. Yöntem ayak izindeki orta ayak izinin, MLA'nın morfolojik yapısını yansıtması esasına dayanır. Buna göre yüksekliği azalmış MLA, daha geniş bir orta ayak izi ile karşımıza çıkar, bunun tam tersi de söz konusudur. Böylece ayak, düşük, normal ve yüksek arklı ayak olarak sınıflandırılır. Schwartz'ın 1928 yılında tarif ettiği "ayak açısından" bu yana ayak izi değerlendirmesinde çeşitli parametre ve ölçüm yöntemleri tanımlanmıştır (24). Ark indeks (3), Staheli indeks (Si) (12), Chippaux-Smirak indeks (CSi) (20) ve Grivas klasifikasyon sistemi (GKS) (14) üzerinde diğerlerinden daha fazla durulan ölçüm yöntemleridir.

Ark indeks, alan hesabına dayanmaktadır ve hesaplanması kolay değildir, dolayısıyla uzun zaman gerektirir (3). Bu yüzden çalışmamızda ark yüksekliği değerlendirmesinde diğer 3 yöntem tercih edilmiştir. Basit ve kolay olması dışında bu 3 ölçüm yönteminin seçilmesinde diğer bir nedeni, MLA yükseklik kaybını değerlendirirken Si'de topuk izinin, CSI'de metatarsal izin, GKS'de ise tüm orta ayak genişliğinin değerlendirmeye katılıyor olmasıydı.

Çalışmamızda, 338 olgunun ayak izleri CSI, Sì ve GKS'ye göre değerlendirildiğinde bulunan pes planus oranları (sırasıyla \%34,9, $\% 18,6, \% 2,6)$ büyük farklılık göstermiştir. Bu sonuç, ayak izi kullanılarak elde edilen pes planus görülme sıklığının tercih edilen ölçüm yöntemine göre büyük değişiklikler gösterebileceğini ortaya koymaktadır. Literatürde ayak izi için tanımlanmış farklı ölçüm yöntemlerinin aynı popülasyonda karşılaştıııldığı bir çalışmaya ulaşamadık. Ancak değiş̧ik ölçüm yöntemlerinin kullanıldığı epidemiyolojik çalışmalarda \%1,1 (14) ila \%43,2 (18) arasında değişen pes planus oranlarının bildirilmiş olması, çalışmamızda ortaya çıkan sonucu destekler niteliktedir.

Çalışmamızda, CSi \%34,9 ile en yüksek pes planus oranını veren ayak izi ölçüm yöntemiydi. CSi, erişkin pes planus araştırmalarında kullanılıyor olmasına karşın, daha çok çocukluk çağı pes planus değerlendirmesi için tercih edilen bir ölçüm yöntemidir $(20,25,26)$. Bu ölçüm yönteminde elde edilen yüksek pes planus insidansı, belki de pes planus için kabul ettiği 0,4 oranının erişkinlerde pes planus tanısını tam anlamıyla karşılayamamasından kaynaklanmaktadır.

Sil ile elde edilen oran ise \%18,6 idi. Bu sonuç, literatür bilgileri ile parallelik göstermektedir (16). Ancak klinik gözlemlerimize göre Si, ark yapısının normal olduğu olgularda bile topuk izinin dar olması durumunda -literatürde benzer bir yoruma ulaşılamadı ise de- pes planus tanısı koydurmaktadır. Bu da, Si indeks için pes planus sıklığını arttıran bir faktör olarak yorumlanabilir.
En düşük pes planus oranı $(\% 2,6)$ GKS ölçümlerinde elde edildi. Bu sonuç literatür bilgileri ile uyum göstermekteydi (14). GKS 6 farklı ayak tipi tanımlamaktadır. Tip 1 ve 2 yüksek arklı ayak, Tip 3 ve 4 normal arklı ayak, Tip 5 ve 6 düşük arklı ayak. Dolayısıyla bu sistem normal ark yüksekliğine sahip ayaktan pes planus veya pes cavusa geçişte "ara formların" tanımlanmasına olanak tanımaktadır. Bu özelliği ile Si ve CSI'den farklılık gösterir. Nitekim Sì ve CSI ile pes planus tanısı almış olguların sırasıyla \%21 ve $\% 29^{\prime}$ u GKS'de geçiş formu olarak isimlendirilebilecek Tip 4 ayak grubunda yeralmaktaydı.

Çalışmamızda Si'ye göre pes planus tespit edilen 52 olgunun basarak çekilen ayak grafilerinde talometatarsal açıya göre 34, talus-zemin açısına göre 14, kalkaneus-zemin açısına göre 12 olguda pes planus tespit edildi. Pes planusun derecelendirmesinde radyografik ölçüm yöntemleri çeşitli araştırmaların konusu olmuştur. İki boyutlu radyolojik görüntülerin 3 boyutlu MLA'nın kompleks anatomik yapısını değerlendirmek için uygun olmadığını savunan (7) ya da ölçümün zorluğundan bahseden (27) yazarların aksine pek çok araştırmacı direk grafileri araştırmalarında kullanmış ve medial longitudinal arkın değerlendirilmesinde radyolojik görüntülemeyi standart ölçüm yöntemi olarak kabul etmiştir $(15,28,29)$. Kanatlı ve ark. (10) çocukluk çağı pes planusunda, TZA ve TMA ile Si arasında korelasyonu ortaya koymuş, kalkaneus zemin açısı ile korelasyon tespit edememiştir. Chen (30) ise yine çocuklarda elektronik olarak elde ettikleri ayakizlerinde Si ve CSİ ile bizim incelediğimiz 3 radyolojik ölçüm yöntemini karşılaştırmışlar ve sadece Si ile TZA arasında korelasyon bulmuşlardır. Çalışmamızda ise her 3 ayak izi ölçüm yöntemi ile TMA ve KZA arasında zayıf korelasyon ortaya kondu ve "pes planus var mı, yok mu?" sorusuna verdikleri cevaplar incelendiğinde, en kuvvetli uyumun GKS ile KZA arasında olduğu görüldü.

Radyografi, MLA'nın osseöz komponentini görüntüler. Genelde kemiksel anomali (vertikal talus, tarsal koalisyon vs.) ile birlikte seyreden rijit pes planusta erken dönemden itibaren tanısal değeri varken, esnek pes planusun ancak ilerleyen dönemlerinde, ayağın bozulan mekaniğinin kemiksel yapıyı bozmaya başlamasından itibaren değer kazanır $(31,32)$. Dolayısıyla esnek pes planusun erken evrelerinde ayak izi ile tanı konan olgularda radyolojik korelasyonun elde edilememesi normal kabul edilebilir. Diğer iki yöntemden, daha az pes planus oranı ortaya koyan GKS'nin, daha önce tartışıldığı gibi, daha "seçici" olması ve pes planus olarak tanımladığı tip 5 ayak tipinin klinik olarak daha ileri pes planus evrelerine uyuyor olması nedeniyle, radyolojik görüntüleme yöntemleri ile uyum göstermesi beklenen bir durumdur. Yine aynı sınıflama sisteminde kemiksel anomali ile giden ciddi pes planus olgularının yer aldığı tip 6 ayak tipine çalışmamızda rastlamadık. Bu sonuca paralel olarak çalışmaya aldığımız ve radyolojik inceleme yaptığımız hiçbir olgumuzda kemiksel bir anomali ile karşılaşmadık. Zaten kemiksel anomali ile seyreden rijid pes planus, daha belirgin şikayet ve fizik muayene bulguları ile, erken yaşlarda farkedilerek genelde cerrahi olarak tedavi edilmektedir ve ayağa yönelik cerrahi müdehale çalışmamızdan dışlanma kriteriydi.

Çalışmamızda kadın olgu sayısının fazla olması eleştirilebilir. Ancak çalışma alanımız bir fakülte hastanesiydi ve incelenen meslek gruplarından biri hemşirelerdi. Çalışmamıza alınan 76 hemşirenin 1'i dışında kadın olması ortaya çıkan bu tablonun sorumlusu olarak gösterilebilir. Ayrıca pes planus gruplarında 
kadın lehine olan niceliksel fark, başlangıç grubu ile aynı oranda idi. Bu da, cinsiyet farkının çalışmanın sonucunu etkilemediğinin bir göstergesi olabilir.

Literatür bilgisi olmasa da, klinik tecrübemiz, Harris-Beath tabakası kullanarak 1 dakika ara ile alınan 2 ayak izinde bile, ayak izi alma prosedürü ne kadar iyi uygulanırsa uygulansın, yaklaşık \%5'lik bir farkın olabileceğini göstermiştir. Aynı şekilde, ayak izi ölçümünü yapan kişiye göre sonuçlar aynı oranda farkılık gösterebilmektedir. Bu nedenle her olgu için birden fazla ayak izi alınarak bunların ortalama sonuçlarının alınmaması ve 2 farklı araştırmacı tarafından ayak izlerinin ayrı ayrı değerlendirilmemesi çalışmamızda diğer bir eksiklik olabilir.

Sonuç olarak, hastanemizde çalışan 338 kişinin ayak izlerinin incelenmesinde pes planus sıklığı CSI'ye göre \%34,9, Si'ye göre $\% 18,8$, GKS'ye göre \%2,6 olarak bulundu. Si, CSi ve GKS'nin birbirleri ile kuvvetli korelasyon gösterdikleri ancak pes planus tanısında verdikleri cevapların istatistiksel olarak uyumsuz olduğu ortaya kondu. Radyolojik değerlendirme metodlarından TMA ve KZA ile 3 ayak izi ölçüm yöntemi arasında zayıf korelasyon bulundu. Pes planus tanısında verdikleri yanıtlar açısında istatistiksel uyum ise sadece GKS ile KZA arasında tespit edildi.

Bu sonuç, farklı ayak izi ölçümü ve radyolojik değerlendirme yöntemlerinin pes planus tanısında, korelasyon gösterse de, uyumsuz sonuçlar ortaya koyabileceğini göstermektedir. Bu nedenle kullanılan yöntemlerin standardizasyonunun sağlanması amacıyla daha geniş katılımlı, örneklem grubunun daha iyi seçildiği, daha fazla ölçüm yönteminin ve klinik bulgunun karşılaştıııldığı yeni çalışmalara ihtiyaç duyulmaktadır.

\section{Çıkar Çatışması:}

Yazarlar herhangi bir çıkar çatışması bildirmemişlerdir.

\section{Kaynaklar}

1. Lee MS, Vanore JV, Thomas IL, Catanzariti AR, Kogler G, Kravitz SR, et al. Diagnosis and treatment of adult flatfoot. I Foot Ankle Surg 2005:44:78-113.

2. Kim HW, Weinstein SL. Flatfoot in children: differential diagnosis and management. Curr Orthop 2000;14:441-7.

3. Cavanagh PR, Rodgers MM. The arch index: a useful measure from footprints. J Biomech 1987;20:547-51.

4. Rose GK, Welton EA, Marshall T. The diagnosis of flatfoot in the child. J Bone Joint Surg Br 1985;67:71-8.

5. Cilli F, Pehlivan O, Keklikçi K, Mahiroğulları M, Kuşkucu M. Prevalence of flatfoot in Turkish male adolescents. Eklem Hastalik Cerrahisi 2009;20:90-2.

6. Rodriguez N, Volpe RG. Clinical diagnosis and assessment of the pediatric pes planovalgus deformity. Clin Podiatr Med Surg 2010;27:43-58.

7. McPoil TG, Vicenzino B, Cornwall MW, Collins N. Can foot anthropometric measurements predict dynamic plantar surface contact area? J Foot Ankle Res 2009;28:2.

8. Atamturk D. Relationship of flatfoot and high arch with main anthropometric variables. Acta Orthop Traumatol Turc 2009;43:254-9.

9. Cobey JC, Sella E. Standardizing methods of measurement of foot shape by including the effects of subtalar rotation. Foot Ankle 1981;2:30-6.

10. Kanatlı $U$, Yetkin $H$, Cila E. Footprint and radiographic analysis of the feet. J Pediatr Orthop 2001;21:225-8.
11. Cavanagh PR. Ultrasonic quantification of the arch of the weightbearing foot. In: Winter DA, Norman RW, Wells RP, Hayes KC, Patla AE, editors. Biomechanics IX-B. Illionis, USA: Human Kinetics Publishers; 1985. p. 211-6.

12. Staheli LT, Chew DE, Corbett M. The longitudinal arch. A survey of eight hundred and eighty-two feet in normal children and adults. J Bone Joint Surg 1987;69:426-8.

13. Gilmour JC, Burns $Y$. The measurement of the medial longitudinal arch in children. Foot Ankle Int 2001;22:493-8.

14. Stavlas P, Grivas TB, Michas C. Vasiliadis E, Polyzois V. The evolution of foot morphology in children between 6 and 17 years of age: a crosssectional study based on footprints in a Mediterranean population. J Foot Ankle Surg 2005;44:424-8.

15. Saltzman CL, Nawoczenski DA, Talbot KD. Measurement of the medial longitudinal arch. Arch Phys Med Rehabil 1995;76:45-9.

16. Harris Rl, Beath T. Army foot survey: an investigation of foot ailments in Canadian soldiers. Ottawa: National Research Council of Canada, 1947. In Rose GK, Welton EA, Marshall T. The diagnosis of flatfoot in the child. J Bone Joint Surg (Br) 1985;67:71-8.

17. Igbigbi PS, Msamati BC. The footprint ratio as a predictor of pes planus: a study of indigenous Malawians. I Foot Ankle Surg 2002;41:394-7.

18. Igbigbi PS, Msamati BC, Shariff MB. Arch index as a predictor of pes planus: a comparative study of indigenous Kenyans and Tanzanians. J Am Podiatr Med Assoc 2005;95:273-6.

19. Abdel-Fattah MM, Hassanin MM, Felembane FA, Nassaane MT. Flatfoot among Saudi Arabian army recruits: prevalence and risk factors. East Mediterr Health J 2006;12:211-7.

20. Stavlas P, Grivas TB, Michas C, Vasiliadis E, Polyzois V. The evolution of foot morphology in children between 6 and 17 years of age: a crosssectional study based on footprints in a Mediterranean population. J Foot Ankle Surg 2005;44:424-8.

21. Simons GW. A standardized method for the radiographic evaluation of clubfeet. Clin Orthop 1978;135:107-18.

22. Vanderwilde R, Staheli LT, Chew DE, Malagon V. Measurements on radiographs of the foot in normal infants and children. J Bone Joint Surg Am 1988;70:407-15.

23. Coughlin MJ, Kaz A. Correlation of Harris mats, physical exam, pictures, and radiographic measurements in adult flatfoot deformity. Foot Ankle Int 2009;30:604-12.

24. Cavanagh PR, Rodgers MM. The arch index: a useful measure from footprints. J Biomech 1987;20:547-51.

25. Dowling AM, Steele J, Bauer LA. Can static plantar pressures of prepubertal children be predicted by inked footprints. J Am Podiatr Med Assoc 2004;94:429-33.

26. Echarri JJ, Francisco F. The development in footprint morphology in 1851 Congolese children from urban and rural areas and the relationship between this and wearing shoes. Leg and Foot 2003;12:141-6.

27. Sensiba PR, Coffey MJ, Williams NE, Mariscalco M, Laughlin RT. Interand intraobserver reliability in the radiographic evaluation of adult flatfoot deformity. Foot Ankle Int 2010;31:141-5.

28. Rao UB, Joseph B. The influence of footwear on the prevalence of flat foot: a survey of 2300 children. J Bone Joint Surg Br 1992; 74:525-7.

29. Pehlivan Ö, Cilli F, Mahiroğulları M, Karabudak O, Köksal O Radiographic correlation of symptomatic and asymptomatic flexible flatfoot in young male adults. Int Orthop 2009;33:447-50. Epub 2008 Jan 15.

30. Chen $\mathrm{CH}$, Huang $\mathrm{MH}$, Chen TW, Weng MC, Lee $\mathrm{CL}$, Wang G]. The correlation between selected measurements from footprint and radiograph of flatfoot. Arch Phys Med Rehabil 2006;87:235-40.

31. William R, Ledoux A, Howard $\mathrm{JH}$. The distributed plantar vertical force of neutrally aligned and pes planus feet. Gait Posture 2002;15:1-9.

32. Aquino A, Payne C. Function of the plantar fascia. Foot 1999;9:73-8. 